\title{
Heat of Formation of Aluminum Fluoride by Direct Combination of the Elements
}

\author{
Eugene S. Domalski and George T. Armstrong
}

(November 16, 1964)

\begin{abstract}
The standard heat of formation of aluminum fluoride was calculated from the heats of combustion of Teflon and of aluminum-Teflon mixtures in fluorine. The heat measurements were made in a bomb calorimeter.

$$
\begin{gathered}
\mathrm{C}_{2} \mathrm{~F}_{4}(\text { solid polymer })+2 \mathrm{~F}_{2}(\mathrm{~g})=2 \mathrm{CF}_{4}(\mathrm{~g}) \\
\mathrm{Al}(\mathrm{c})+3 / 2 \mathrm{~F}_{2}(\mathrm{~g})=\mathrm{AlF}_{3}(\mathrm{c})
\end{gathered}
$$

For reaction (1), $\Delta H_{298}^{\circ}$ was found equal to $-10,350.7 \pm 0.4 \mathrm{Jg}^{-1}(-247.43 \pm 0.01 \mathrm{kcal}$ monomole ${ }^{-1}$ ), and for reaction (2) $\Delta H_{298}^{\circ}=\Delta H_{f 298}^{\circ}$ was calculated to be $-1507.8 \pm 1.2 \mathrm{~kJ}$ mole $^{-1}\left(-360.37 \pm 0.29 \mathrm{kcal}^{\mathrm{mole}}{ }^{-1}\right)$. The latter uncertainties are the computed standard deviations of the means. The calculated standard heat of formation of aluminum fluoride is estimated to be accurate to within $\pm 6.6 \mathrm{~kJ} \mathrm{~mole}^{-1}\left(1.6 \mathrm{kcal} \mathrm{mole}{ }^{-1}\right)$. The measurements on Teflon were combined with existing data and the heat of formation of carbon tetrafluoride was calculated to be $-221.8 \mathrm{kcal} \mathrm{mole}^{-1}$.
\end{abstract}

\section{Introduction}

Considerable difficulty has been encountered in determining the heat of formation of crystalline aluminum fluoride, and until about ten years ago no complete determination had been made. The most obvious procedure would have been to determine the heat of solution of $\mathrm{AlF}_{3}$ (c) in an aqueous solvent, and to combine the result with the known heats of formation of $\mathrm{Al}^{+3}(\mathrm{aq})$ and $\mathrm{F}^{-}(\mathrm{aq})$. This procedure is not practicable because of the low solubility and slow rate of solution of $\mathrm{AlF}_{3}(\mathrm{c})$ in appropriate solvents.

In the early studies by Baud [1, 2], ${ }^{1}$ a value for the heat of formation of aluminum fluoride was calculated from heat of solution measurements on two hydrates of aluminum fluoride in conjunction with an estimate of the heat of hydration of anhydrous aluminum fluoride. Subsequent estimates of the heat of formation of $\mathrm{AlF}_{3}(\mathrm{c})$ by von Wartenberg [3], Bichowsky and Rossini [4], Rossini et al. [5], and Brewer $[6]$ used Baud's estimate of the heat of hydration of anhydrous aluminum fluoride as part of their calculation. Later work has shown that these estimates were in error by 25 to $50 \mathrm{kcal} \mathrm{mole}^{-1}$.

In 1954, Gross, Hayman, and Levi [7] studied reaction (1), for which they found

$$
\mathrm{Al}(\mathrm{c})+\frac{3}{2} \mathrm{PbF}_{2}(\mathrm{c})=\mathrm{AlF}_{3}(\mathrm{c})+\frac{3}{2} \mathrm{~Pb}(\mathrm{c}) .
$$

\footnotetext{
${ }_{1}$ Figures in brackets indicate the literature references at the end of this paper.
}

$\Delta H_{298}^{\circ}=-118.53 \pm 0.08 \mathrm{kcal}$ mole ${ }^{-1}$. Using their measurement and the known heat of formation of $\mathrm{PbF}_{2}(\mathrm{c}),-158.5$ kcal mole ${ }^{-1}[5]$, they reported $\Delta H_{f 298}^{\circ}\left[\mathrm{AlF}_{3}(\mathrm{c})\right]=-356.3 \pm 0.3 \mathrm{kcal} \mathrm{mole}^{-1}$. In later work, Gross, Hayman, and Levi [8] measured the heat of reaction (2) to be $-138.31 \pm 0.12 \mathrm{kcal}$ mole $^{-1}$

$$
3 \mathrm{NaF}(\mathrm{c})+\mathrm{Al}(\mathrm{c})+\frac{3}{2} \mathrm{PbF}_{2}(\mathrm{c})=\mathrm{Na}_{3} \mathrm{AlF}_{6}(\mathrm{c})+\frac{3}{2} \mathrm{~Pb}(\mathrm{c}) .
$$

Combining this value with their value for the heat of reaction (1) and Coughlin's values [9] for the heats of formation of $\mathrm{NaF}(\mathrm{c})$ and $\mathrm{Na}_{3} \mathrm{AlF}_{6}$ (c), they obtained $\Delta H_{f 298}^{\circ}\left[\mathrm{AlF}_{3}(\mathrm{c})\right]=-356.15 \mathrm{kcal} \mathrm{mole}^{-1}$, a value independent of the heat of formation of $\mathrm{PbF}_{2}(\mathrm{c})$. Gross suggested [8] that since the heats of formation of all the fluorides involved in these calculations are dependent on that of hydrogen fluoride, an independent determination of the heat of formation of a metal fluoride by combustion of the metal in fluorine would be valuable.

After our work was well under way, Kolesov, Martynov, and Skuratov [10] reported a study of reaction (1). They found $\Delta H_{298}^{\circ}=-117.7 \pm 0.6 \mathrm{kcal}$ mole $^{-1}$ on the basis of 24 measurements, and calculated the heat of formation of aluminum fluoride to be $-357 \pm 2 \mathrm{kcal} \mathrm{mole}^{-1}$.

In view of the large discrepancy between the values calculated by Gross and his co-workers and those 
that had been previously estimated, we undertook a determination of the heat of formation of aluminum fluoride by direct combination of the elements in a bomb calorimeter. Since investigations by Hubbard and co-workers [11] had demonstrated the feasibility of bomb calorimetry with fluorine as the oxidizer, it seemed likely that this technique would lead to an unambiguous result.

We feel our results show the substantial correctness of the measurements of Gross et al. and Kolesov et al. The agreement between their results and ours is improved by application of new information on the heat of formation of hydrogen fluoride to the auxiliary data required in their calculations. This improvement tends to substantiate a more negative value for the heat of formation of hydrogen fluoride than until recently has been accepted.

\section{Preliminary Experiments}

In preliminary experiments made to determine optimum reaction conditions under which aluminum metal would burn in a combustion bomb filled with fluorine, a variety of sample forms was tried including pellets, foil, and loose powder. It was found that massive samples such as pellets or large pieces of foil would either short circuit the fuse or fail to ignite from the energy supplied by the fuse. In these experiments a coiled aluminum wire was used as a fuse. Aluminum foil cut into narrow shreds $(2.5 \mathrm{~cm} \times 0.025 \mathrm{~cm} \times 0.0025 \mathrm{~cm})$ and loosely packed together, reacted very rapidly but only to about 75 percent completion. From inspection of the inner walls of the bomb after such an experiment, and from observation of reactions in a glass combustion vessel, it was evident that shortly after the combustion began, burning pieces of aluminum were thrown out of the reaction zone and quenched on contact with the cold bomb walls. It was difficult to determine the amount of unburned aluminum which was intermixed with the combustion product.

A few experiments were performed in which loose aluminum powder contained in a thermoplastic Teflon bag was burned in fluorine. Only 30 to 50 percent of the aluminum powder reacted. Considerable amounts of carbon were present in the products as the result of incomplete combustion of the Teflon bag. This technique was therefore considered to be unsatisfactory.

A sample geometry and environment were found which confined the sample to the reaction zone and provided other desirable characteristics. A mixture of finely divided aluminum powder and finely divided Teflon powder was compressed into a pellet which was supported on a stainless steel or monel plate. With this preparation, reactions were found to go essentially to completion (99 to 100 percent). The Teflon made ignition easy because of the low thermal conductivity it imparted to the pellet. In addition it acted as a moderator and maintained a temperature conducive to burning. No appreciable attack of fluorine on the bomb parts occurred when this procedure was used.

\section{Materials}

The aluminum used for samples was in the form of a powder and was supplied with the following analysis of metallic impurities: silicon, 0.06 percent; iron, 0.07 percent; and copper, 0.005 percent. Microscopic examination revealed that it consisted of irregularly shaped particles ranging in approximate dimensions from 10 to $160 \mu$; the average particle size was determined to be $26 \mu$ by a sub-sieve sizer. Because of the small particle size and the correspondingly large surface area, the sample was tested for the presence of oxide. Investigations [12], both experimental and theoretical in nature, have estimated the thickness of the oxide layer on thin aluminum films to be 20 to $50 \AA$ in air at room temperature. If a surface film of $\mathrm{Al}_{2} \mathrm{O}_{3} 50 \mathrm{~A}$ thick were presumed to exist on smooth-surfaced cubes of aluminum $26 \mu$ on edge, the aluminum would contain 0.28 percent $\mathrm{Al}_{2} \mathrm{O}_{3}$ by weight. Because this amount would cause a significant correction to the heat of combustion, determination of the actual amount of alumina was necessary.

The NBS Analysis and Purification Section used two methods to determine the amount of alumina. In the first method aluminum powder was heated in an atmosphere of argon until the powder melted and the oxide floated to the surface. The oxide was then treated by the method of Werner [13] in which the aluminum is dissolved by a bromine-methanol mixture leaving the $\mathrm{Al}_{2} \mathrm{O}_{3}$ as a residue.

In the second method, a stream of dry argon saturated with bromine was passed over the aluminum in a furnace. Aluminum bromide distilled off leaving an aluminum oxide residue which was weighed. The values for the $\mathrm{Al}_{2} \mathrm{O}_{3}$ content determined by the two methods were 0.46 and 0.47 percent, respectively, and the average of all the individual determinations was 0.468 percent.

The Teflon powder used was a commercial preparation designated as TFE Fluorocarbon Resin, "Teflon 5". It was composed of irregularly shaped particles which tended to adhere to one another. Particle dimensions ranged from 50 to 800 microns, as observed by examination with a microscope. The Teflon was not modified or specially treated before use.

The fluorine gas was analyzed by absorbing the fluorine in mercury and observing the residual pressure of unreacted gases [14]. The fluorine was found to be 99 percent pure. The residual gases were examined in a mass spectrometer and the impurities were found to be, in mole percent of the original sample: $\mathrm{O}_{2}, 0.9 ; \mathrm{N}_{2}, 0.08 ; \mathrm{CO}_{2}, 0.01$; with smaller amounts of $\mathrm{SiF}_{4}, \mathrm{HF}$, fluorocarbons and other compounds that were not definitely identified.

\section{Calorimetric Āpparatus}

An isothermal-jacket, stirred-water calorimeter was used, which was a modification of the Dickinson design [15] by Prosen and co-workers [16]. A single 
motor mounted on an insulated bracket on the jacket wall was used to stir the water in both the jacket and the calorimeter vessel by a pulley arrangement. The stirrer was coupled to the motor by a pulley to minimize heat transfer from the motor to the jacket. The jacket water was maintained at a constant temperature near $30{ }^{\circ} \mathrm{C}$ with a range of $0.005{ }^{\circ} \mathrm{C}$ by a commercial thermoregulator having a temperature sensitive resistor as a sensing element.

Temperatures were measured with a G-2 Mueller bridge in conjunction with a 25-ohm platinumresistance thermometer. The latter was immersed in the calorimeter vessel near the wall. Temperatures were read to $0.0001{ }^{\circ} \mathrm{C}$.

Reactions were conducted in a commercially available combustion bomb shown in figures 1 and 2 , which is suitable for handling fluorine as the oxidant. The bomb was fabricated from "A" nickel, and has a volume of approximately $360 \mathrm{~cm}^{3}$. The pelleting device is shown in figure 2 along with the electrode-fuse arrangement and pellet holder used in the experiments of series I.

The standard initial calorimeter for the experiments of series I consisted of the combustion bomb with aluminum fuse supports, Chromel C fuse wire, monel pellet holder and 21 atmospheres of fluorine at $303.2^{\circ} \mathrm{K}$, the electrical heater, the resistance thermometer and the calorimeter vessel with a measured quantity of water. The mass of the calorimeter vessel, plus water, was 3700.0 g. For the experiments of series II, the standard initial calorimeter was the same as for series I except for the addition of a liner inside the bomb, slight modifications in the fuse, fuse supports, and pellet holder.

Some electrical calibration experiments were carried out using a heater of novel design. The heater consisted of an insulated Advance wire inside an annealed copper tube. The tube was flattened and coiled to fit the combustion bomb. Because of excessive thermal conduction through the heater connections to the outside, the electrical calibration experiments are not considered to be valid. However, because the results of the electrical calibration must be included in order to give an adequate description of the combustion experiments, the electrical instruments will be listed briefly.

The equipment used in measuring the power supplied to the calorimeter consisted of a WolffDieselhorst potentiometer, a $0.01 \mathrm{ohm}$ Reichsanstalttype standard resistor, a volt box with a ratio of 20,000 to $20 \mathrm{ohms}$, a thermostated Weston standard (saturated) cell, and the $10.6 \mathrm{ohm}$ heater. Current through the heater was turned on and off by a manually operated DPD'T copper knife-switch. An electronic timer with a resolution of $10^{-5}$ seconds was triggered to operate by the appearance and disappearance of the voltage on the heater, and thus recorded the elapsed time of heating. The time base was the NBS standard frequency signal of 100 $\mathrm{kc} / \mathrm{s}$. A standard frequency time signal $(60 \mathrm{c} / \mathrm{s})$ was used to operate a recording clock for timing the rapid temperature rise of the calorimeter.
Standard frequency time signals (one per second) were used to time the initial and final drift periods.

Procedures used in making the heat measurements have been adequately described elsewhere [17, 18].

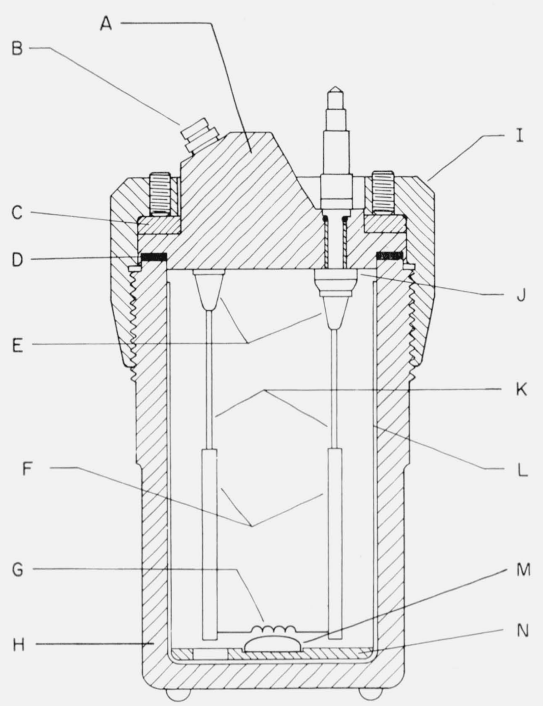

Figure 1. Inner arrangement of the fluorine combustion bomb.

A, nickel bomb head; $\mathrm{B}$, needle valve; $\mathrm{C}$, monel pressure plate; D, Teflon gasket; E, monel lock nut; F, aluminum electrode; G, fuse; H, bomb body; I, screw cap; J, alumina washer; K, monel rod; L, type 304 stainless steel liner; M, pellet; N, pellet holder.

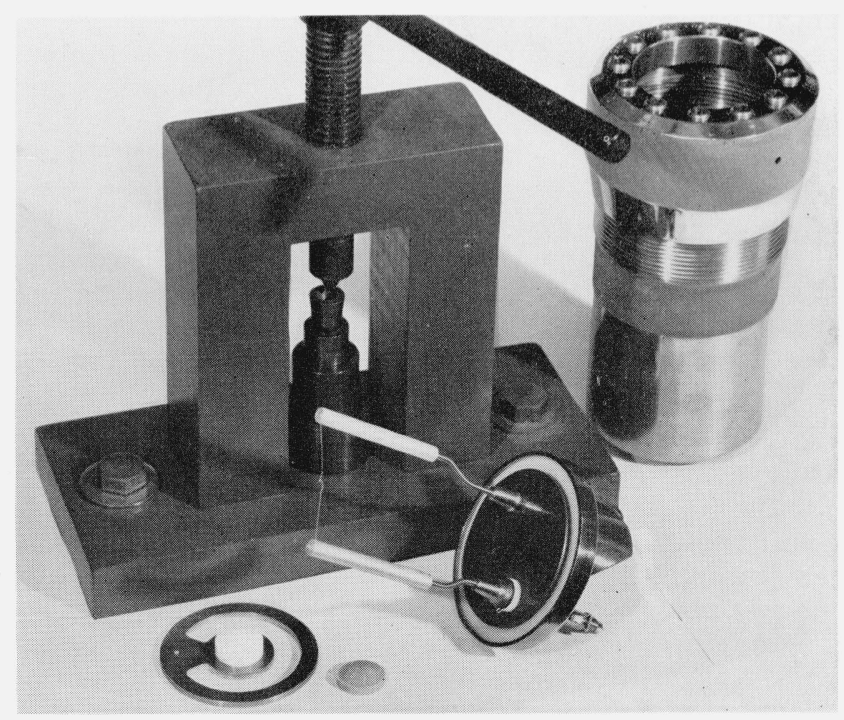

Figure 2. Pellet press used in sample preparation and electrode-fuse arrangement.

Foreground: monel pellet holder with Teflon sample, aluminum-Teflon sample nearby, bomb head showing electrode-fuse arrangement for series I experiments. Background: pellet press, die pieces, and bomb body with serew cap. 


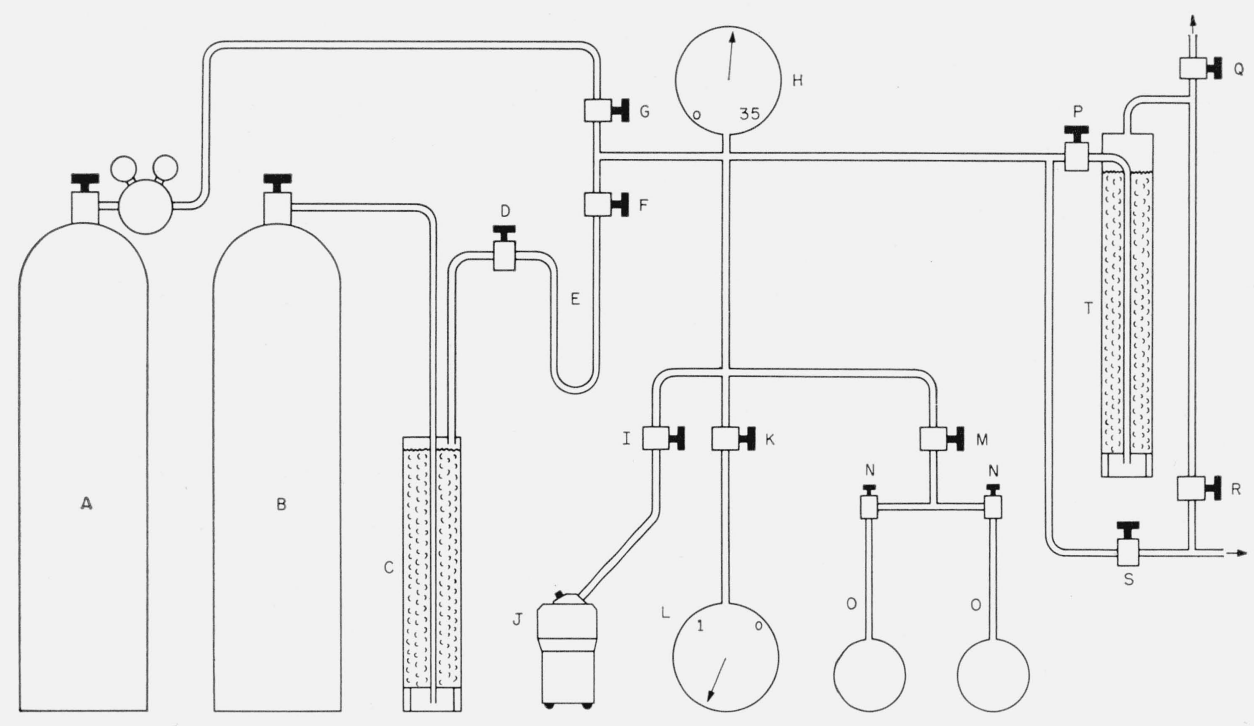

Figure 3. Schematic diagram of fluorine manifold. A, helium; B, fluorine; C, hydrogen fluoride trap; D, fluorine valve; E, liquid nitrogen trap for fluorine; F, fluorine
valve to manifold; G, helium valve to manifold; $\mathrm{H}$, pressure gage ( 0 -35 atm); I, valve to bomb; J, bomb; K, valve to vacuum gage; L, vacuum gage (0-1 atm); M, N, valves to gas-sample collector bulbs; O, gas-sample collector bulbs; P, valve to fluorine absorption tower; $Q$, vent valve to fume hood; $R$, valve to vacuum via fluorine absorption tower; S, valve direct to vacuum; T, fluorine absorption tower.

\section{Fluorine Manipulation}

A manifold for handling fluorine, shown in figure 3 , was used with its attachments for (1) filling: and emptying the combustion bomb, (2) obtaining samples of volatile products of combustions and (3) obtaining samples of fluorine for analysis. The manifold consisted of $1 / 4$ in. monel tubing (wall thickness 0.035 in.) connecting a series of commercially available packless unions, T-connectors and valves. The valves, T-connectors, and unions were made of monel or stainless steel and were silver soldered to the monel tubing. Some copper couplings were also used.

To the manifold were attached cylinders of helium, $\mathrm{A}$, and fluorine, B, gas sampling bulbs, $\mathrm{O}$, a fluorine absorption tower, T, a vacuum system (not shown), and two Bourdon gages, L, and $\mathrm{H}$, specially constructed for fluorine service. Of the Bourdon gages, $\mathrm{H}$ was used for measuring pressure over the range 0 to $35 \mathrm{~atm}$ abs and $\mathrm{L}$ was for indicating rough vacuum from zero $(2.5 \mathrm{~mm} \mathrm{Hg})$ to $1.0 \mathrm{~atm}$. A thermocouple gage in the vacuum system was used to measure pressures below $10^{-1} \mathrm{~mm} \mathrm{Hg}$. A mechanical pump provided a sufficiently good vacuum for work with the fluorine handling system. The system was considered to be sufficiently gastight for use if no indication of leaks was found at internal pressures of either $35 \mathrm{~atm}$ or $0.005 \mathrm{~mm} \mathrm{Hg}$.

In order to fill the combustion bomb, J, with fluorine, it was attached to the manifold by a screw connector. With valves F, G, M, P, R closed and valves $\mathrm{I}, \mathrm{K}, \mathrm{S}$, and the bomb needle valve open, the bomb was evacuated to a pressure of $10^{-2} \mathrm{~mm}$ $\mathrm{Hg}$. When this degree of vacuum was attained, valves $\mathrm{K}$ and $\mathrm{S}$ were closed, and fluorine was introduced into the bomb by opening the fluorine tank valve, and then valves $D$ and $F$. The rate of flow was regulated to allow the pressure to increase about four atm per minute. When the gage pressure was about $21 \mathrm{~atm}$, valve $\mathrm{F}$ and the bomb needle valve were closed, then valve $D$ and the fluorine tank valve. If the pressure in the tank was less than 21 atm, a small section of the line, E, was immersed in liquid nitrogen and fluorine was condensed in it. By allowing the condensed fluorine to evaporate and regulating the backflow through valve $D$, a pressure of 21 atm could be obtained in the bomb. After the bomb had been filled and valve D was closed, the residual fluorine in the manifold was diluted with helium. The gas mixture was slowly passed through valve $\mathrm{P}$ and into the fluorine absorption tower. The absorbent used was soda lime. The rate of flow was adjusted to reduce the pressure about 4 atm per minute until the pressure was atmospheric. Gases passing through valve Q emerged near the top of the fume hood in which the apparatus was located into the path of the up-draft. The manifold and absorption tower were filled with helium to a pressure of about $8 \mathrm{~atm}$ through valve $\mathrm{G}$, and then valve $\mathrm{Q}$ was opened to release the gases. The purging procedure was performed three times. Then after valve $Q$ was closed, valve $R$ was opened and the system was pumped out through the absorption tower. When the pressure reached about $5 \mathrm{~mm}$ $\mathrm{Hg}$, valve I was closed and the loaded combustion bomb was removed from the fluorine manifold. 
In order to remove fluorine remaining in the bomb after an experiment, and to obtain samples of other gaseous products of combustion, the bomb was again attached to the manifold. Removal of fluorine was done using much the same procedure as described above, except that the bomb needle-valve remained open until evacuation was complete. The bomb was then filled with one atmosphere of helium and was ready to be opened.

To obtain a sample of bomb gases before completely emptying of the bomb, bulbs at $\mathrm{O}$ were used. If the interest was in the gaseous constituents other than fluorine, the bulb contained a little mercury which by gentle shaking absorbed the fluorine after the bulb had been filled.

\section{Calibration Experiments}

Each series of combustion measurements (series I and II, described later) was accompanied by an electrical calibration in which conditions were the same as in the measurements. Following the experimental measurements on Teflon and the aluminum-Teflon mixtures, two other series of calibration experiments were made.

Series III consisted of calibration experiments in which benzoic acid (Standard Sample 39h) was used as a reference material and was burned in oxygen at $30 \mathrm{~atm}$ pressure. The energy of combustion of benzoic acid in the standard bomb process is 26434 $\mathrm{Jg}^{-1}$. Also present in the bomb were a platinum crucible to hold the sample, one $\mathrm{ml}$ of distilled water, and a two-cm piece of Chromel $\mathrm{C}$ fuse wire (diam $0.16 \mathrm{~mm}$ ) supported over the sample by platinum wire leads. The oxygen used was of high purity (99.996 percent) and no nitric acid correction was required after a combustion experiment. This was checked by measuring the $p \mathrm{H}$ of the solution in the bomb after each experiment.

A discrepancy of about 0.17 percent between the chemical calibration and previous electrical calibrations was indicated by series III. Because of an uncertainty, mentioned in section 4 , associated with the electrical calibration experiments, the calibration with benzoic acid, series III, is preferred over the electrical measurements.
Because the bomb had been changed after series I and II and before series III another electrical calibration, series IV, was carried out in order to determine accurately the correction factor to be applied to the measurements of series I and series II. For series IV the bomb, its contents, and other conditions were the same as the initial conditions of the benzoic acid calibration experiments. The heater was present in both the chemical and electrical calibration experiments.

Six experiments with benzoic acid in series III lead to a mean energy equivalent of $143,038.9$ $\pm 15.6 \mathrm{~J} \mathrm{ohm}^{-1}$. The electrical calibration of series IV leads to a value of $143,276.5 \pm 16.0 \mathrm{~J}$ $\mathrm{ohm}^{-1}$ based also on six experiments. The six electrical calibration experiments of series I, adjusted by the factor $143,038.9 / 143,276.5$ lead to an energy equivalent of $143,725.5 \pm 13.5 \mathrm{~J} \mathrm{ohm}^{-1}$. Similarly, the five electrical calibration experiments of series II, adjusted by the same factor lead to an energy equivalent of $144,097.7 \pm 14.0 \quad \mathrm{~J} \mathrm{ohm}^{-1}$. The uncertainties cited above are the standard deviations of the means computed from the data.

The differences in the observed energy equivalent are due to small differences in the bomb and its contents which have been discussed. Each series of heat measurements was calculated using the appropriate energy equivalent.

\section{Combustion Experiments}

Two complete series of combustion experiments were carried out, series I and series II. Series I consisted of five combustions of Teflon (table 1), six combustions of aluminum-Teflon mixtures (table 2 ), and the six electrical calibration experiments previously mentioned. This series must be considered in the nature of preliminary experiments, however, it affords substantial support for the later measurements and is therefore described in detail. Series II consisted of five combustions of Teflon (table 3), five combustions of aluminum-Teflon mixtures (table 4), and five electrical calibration measurements.

TABLE 1.-Teflon combustion experiments. Series $I$

\begin{tabular}{|c|c|c|c|c|c|}
\hline Experiment & 1 & 2 & 3 & 4 & 5 \\
\hline 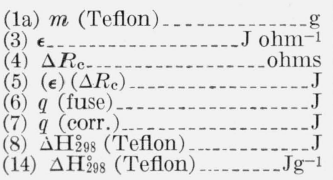 & $\begin{array}{r}4.23389 \\
143,777.8 \\
0.305338 \\
-43,900.8 \\
153.5 \\
30.4 \\
-43,716.9 \\
-10,325.5\end{array}$ & $\begin{array}{r}4.24120 \\
143,778.2 \\
0.305811 \\
-43,971.8 \\
138.5 \\
30.6 \\
-43,802.7 \\
-10,327.9\end{array}$ & $\begin{array}{r}4.24090 \\
143,778.1 \\
0.30611 .7 \\
-44,011.5 \\
138.0 \\
30.6 \\
-43,842.9 \\
-10,338.1\end{array}$ & $\begin{array}{r}4.22823 \\
143,778.2 \\
0.305673 \\
-43,929.1 \\
349.0 \\
30.5 \\
-43,569.6 \\
-10,304.5\end{array}$ & $\begin{array}{r}4.24161 \\
143,778.6 \\
0.306201 \\
-44,025.2 \\
76.0 \\
30.7 \\
-43,918.5 \\
-10,354.2\end{array}$ \\
\hline
\end{tabular}

(16) Mean $\Delta \mathrm{H}_{298}^{2}$ (Teflon) _.........

(18) Standard deviation of the mean $\ldots . . . \ldots \ldots \ldots \ldots \ldots \ldots . . .1 \mathrm{Jg}^{-1}$ 
TABLE 2. Aluminum-Teflon combustion experiments. Series I

\begin{tabular}{|c|c|c|c|c|c|c|}
\hline Experiment & 1 & 2 & 3 & 4 & 5 & 6 \\
\hline 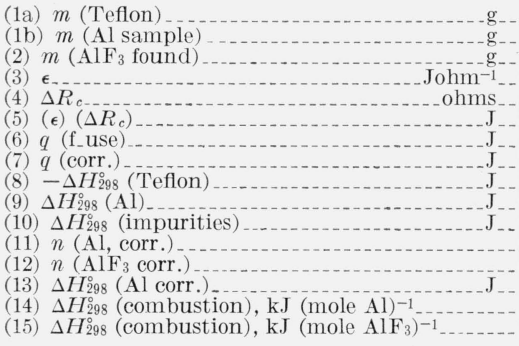 & $\begin{array}{r}2.01775 \\
0.39548 \\
1.2209 \\
143,756.2 \\
0.299379 \\
-43,037.6 \\
170.0 \\
-49.5 \\
20,843.4 \\
-22,073.7 \\
42.8 \\
0.014569 \\
0.014494 \\
-22,030.9 \\
-1512.18 \\
-1520.00\end{array}$ & $\begin{array}{r}2.13988 \\
0.39914 \\
1.2480 \\
143,757.6 \\
0.308698 \\
-44,377.7 \\
370.0 \\
-49.2 \\
22,105.0 \\
-21,951.9 \\
43.1 \\
0.014703 \\
0.014817 \\
-21,908.8 \\
-1490.09 \\
-1478.63\end{array}$ & $\begin{array}{r}2.13602 \\
0.40080 \\
1.2510 \\
143,758.3 \\
0.308887 \\
-44,405.1 \\
195.0 \\
-49.4 \\
22,065.1 \\
-22,194.4 \\
43.1 \\
0.014765 \\
0.014853 \\
-22,151.3 \\
-1500.26 \\
-1491.37\end{array}$ & $\begin{array}{r}2.13445 \\
0.39996 \\
1.2375 \\
143,755.7 \\
0.309101 \\
-44,435.0 \\
226.0 \\
-49.7 \\
22,048.9 \\
-22,209.8 \\
43.1 \\
0.014734 \\
0.014692 \\
-22,166.7 \\
-1504.46 \\
-1508.76\end{array}$ & $\begin{array}{r}2.13814 \\
0.40224 \\
1.2375 \\
143,757.7 \\
0.309993 \\
-44,563.9 \\
221.5 \\
-50.0 \\
22,087.0 \\
-22,305.4 \\
43.2 \\
0.014818 \\
0.014817 \\
-22,262.2 \\
-1502.38 \\
-1502.48\end{array}$ & $\begin{array}{r}2.13529 \\
0.40190 \\
1.2625 \\
143,758.1 \\
0.309959 \\
-44,559.1 \\
308.0 \\
-50.0 \\
22,057.5 \\
-22,243.6 \\
43.2 \\
0.014805 \\
0.014990 \\
-22,200.4 \\
-1499.52 \\
-1481.01\end{array}$ \\
\hline
\end{tabular}

(16) Mean $\Delta H_{298}^{\circ}$ (combustion) $-1501.5 \mathrm{~kJ}\left(\right.$ mole Al) ${ }^{-1} ;-358.87 \mathrm{kcal}\left(\right.$ mole Al) ${ }^{-1}$

(17) Mean $\Delta H_{288}^{\circ}$ (combustion) $-1497.0 \mathrm{~kJ}$ (mole $\left.\mathrm{AlF}_{3}\right)^{-1} ;-357.79 \mathrm{kcal}\left(\text { mole } \mathrm{AlF}_{3}\right)^{-1}$

(18) Standard deviation of the mean $1.6 \mathrm{~kJ}$ (mole Al) ${ }^{-1} ; 0.38 \mathrm{kcal}(\text { mole } \mathrm{Al})^{-1}$

(19) Standard deviation of the mean $6.6 \mathrm{~kJ}\left(\text { mole } \mathrm{AlF}_{3}\right)^{-1} ; 1.6 \mathrm{kcal}\left(\text { mole } \mathrm{AlF}_{3}\right)^{-1}$

Table 3. Teflon combustion experiments. Series II

\begin{tabular}{|c|c|c|c|c|c|}
\hline Experiment & 1 & 2 & 3 & 4 & 5 \\
\hline $\begin{array}{l}\text { (1a) } m \text { (Teflon) } \\
\text { (3) } \epsilon \\
\text { (4) } \Delta R_{c} \\
\text { (5) }(\epsilon)\left(\Delta R_{c}\right) \\
\text { (6) } q \text { (fuse) } \\
\text { (7) } q \text { (corr.) } \\
\text { (8) } \Delta H_{298}^{\circ} \text { (Teflon) } \\
\text { (14) } \Delta H_{298}^{\circ} \text { (Teflon) } \\
\text { (14) J } \\
\end{array}$ & $\begin{array}{r}4.25461 \\
144,153.1 \\
0.306016 \\
-44,113.2 \\
42.7 \\
30.8 \\
-44,039.7 \\
-10,351.1\end{array}$ & $\begin{array}{r}4.23781 \\
144,152.4 \\
0.304855 \\
-43,945.6 \\
45.6 \\
30.5 \\
-43,869.5 \\
-10,351.9\end{array}$ & $\begin{array}{r}4.23486 \\
144,152.4 \\
0.304558 \\
-43,902.8 \\
42.8 \\
30.5 \\
-43,829.5 \\
-10,349.7\end{array}$ & $\begin{array}{r}4.22402 \\
144,152.2 \\
0.303797 \\
-43,793.0 \\
41.8 \\
30.5 \\
-43,720.7 \\
-10,350.5\end{array}$ & $\begin{array}{r}4.26040 \\
144,152.6 \\
0.306424 \\
-44,171.8 \\
44.5 \\
30.8 \\
-44,096.5 \\
-10,350.3\end{array}$ \\
\hline
\end{tabular}

(16) Mean $\Delta H_{298}^{\circ}$ (Teflon)

$-10,350.7 \mathrm{~J} \mathrm{~g}^{-1}$

(18) Standard deviation of the mean.

$0.4 \mathrm{~J} \mathrm{~g}-1$

TABle 4. Aluminum-Teflon combustion experiments. Series II

\begin{tabular}{|c|c|c|c|c|c|}
\hline Experiment & 1 & 2 & 3 & 4 & 5 \\
\hline 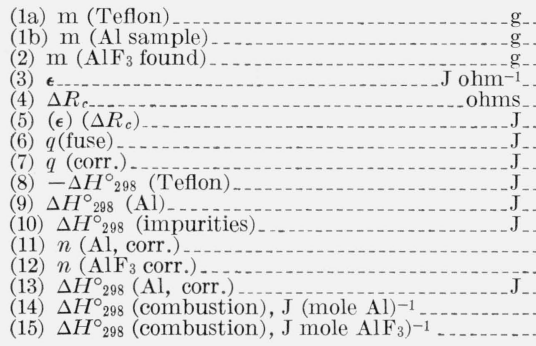 & $\begin{array}{r}2.14074 \\
0.40028 \\
1.2311 \\
144,131.4 \\
0.308652 \\
-44,486.4 \\
49.2 \\
-49.5 \\
22,158.2 \\
-22,328.5 \\
43.1 \\
0.014746 \\
0.014616 \\
-22,285.4 \\
-1511.28 \\
-1524.73\end{array}$ & $\begin{array}{r}2.12728 \\
0.39880 \\
1.2213 \\
144,131.7 \\
0.306706 \\
-44,206.1 \\
49.6 \\
-49.5 \\
22,018.8 \\
-22,187.2 \\
43.0 \\
0.014691 \\
0.014499 \\
-22,144.2 \\
-1507.33 \\
-1527.30\end{array}$ & $\begin{array}{r}2.14192 \\
0.40031 \\
1.2527 \\
144,132.9 \\
0.308567 \\
-44,474.7 \\
50.1 \\
-49.6 \\
22,170.4 \\
-22,303.8 \\
43.1 \\
0.014747 \\
0.014873 \\
-22,260.7 \\
-1509.51 \\
-1496.73\end{array}$ & $\begin{array}{r}2.13963 \\
0.40430 \\
1.2661 \\
144,131.6 \\
0.309709 \\
-44,638.9 \\
50.2 \\
-50.2 \\
22,146.7 \\
-22,492.2 \\
43.4 \\
0.014894 \\
0.015033 \\
-22,448.8 \\
-1507.24 \\
-1493.29\end{array}$ & $\begin{array}{r}2.13579 \\
0.40278 \\
1.2600 \\
144,131.6 \\
0.308498 \\
-44,464.3 \\
49.8 \\
-50.0 \\
22,106.9 \\
-22,357.6 \\
43.2 \\
0.014838 \\
0.014960 \\
-22,314.4 \\
-1503.87 \\
-1491.60\end{array}$ \\
\hline
\end{tabular}

(16) Mean $\Delta H^{\circ}{ }_{298}$ (combustion) $-1507.8 \mathrm{~kJ}\left(\right.$ mole Al) ${ }^{-1} ;-360.37 \mathrm{kcal}\left(\right.$ mole Al) ${ }^{-1}$

(17) Mean $\Delta H^{\circ}{ }_{298}$ (combustion) $-1506.7 \mathrm{~kJ}\left(\text { mole } \mathrm{AlF}_{3}\right)^{-1} ;-360.11 \mathrm{kcal}\left(\text { mole } \mathrm{AlF}_{3}\right)^{-1}$

(18) Standard deviation of the mean $1.2 \mathrm{~kJ}$ (mole Al)-1; $0.29 \mathrm{kcal}$ (mole Al)-1

(19) Standard deviation of the mean $7.9 \mathrm{~kJ}\left(\text { mole }^{-1} \mathrm{AlF}_{3}\right)^{-1} ; 1.9 \mathrm{kcal}\left(\text { mole } \mathrm{AlF}_{3}\right)^{-1}$ 


\subsection{Experimental Conditions and Procedures}

For the combustion of Teflon in both series I and series II, accurately weighed pellets of about $4.25 \mathrm{~g}$ were prepared from powdered Teflon.

For the combustion of mixtures, about $2.13 \mathrm{~g}$ of Teflon and $0.40 \mathrm{~g}$ of aluminum powder were accurately weighed for each experiment. The powders were mixed with a needle, and transferred to a pellet press for pelleting. The aluminum powder adhered to the 'Teflon, and thus transfer was not difficult. The pellet was also accurately weighed; a loss in weight (1.0 to $2.5 \mathrm{mg}$ ) on pelleting was always observed. In calculating the sample mass, we assumed that the loss of the two constituents took place in proportion to the original amount of each. The samples were weighed to $0.01 \mathrm{mg}$.

In series $I$, the mass of aluminum fluoride formed was determined by weighing the bomb head with the electrode-fuse system, and the bomb base with the pellet holder, before and after each experiment. A balance having a capacity of $5 \mathrm{~kg}$ and a readability of $0.5 \mathrm{mg}$ was used for weighing the bomb parts.

The fuse system used in series I was $2-\mathrm{cm}$ piece of Chromel C wire $(0.015 \mathrm{~cm}$ diam) supported on either side by a $3-\mathrm{cm}$ piece of aluminum wire $(0.025$ $\mathrm{cm}$ diam). The mass of the fuse system, i.e., aluminum wires $(8 \mathrm{mg})$ and Chromel $\mathrm{C}(3 \mathrm{mg})$, was 11 $\mathrm{mg}$, and its heat of combustion would be $483.5 \mathrm{~J}$ if it burned completely.

Inspection of the bomb after a combustion showed many small balls of melted fuse adhering to the wall. Determining the amount of melted fuse remaining was difficult because removal of the fuse from the bomb wall almost always resulted in chipping out some of the bomb material itself. Establishing the amount of unburned fuse by weighing the bomb base was also difficult because of the large mass of the bomb base (about $2 \mathrm{~kg}$ ) compared to the spattered fuse $(2$ to $6 \mathrm{mg}$ ). The difficulty was much greater when aluminum was burned bacause fuse pieces could not be easily separated from the aluminum fluoride formed in the combustion.

The difficulties and uncertainties introduced by the fuse were a major factor in the decision to carry out an additional series of experiments on an improved fuse system. The fuse problems in series I are discussed further in section 7.2.

Series II differs in several respects from series I. A liner was inserted into the bomb base in an attempt to facilitate weighing of the aluminum fluoride product. The liner was made of type 304 stainless steel. It had a wall thickness of about $0.25 \mathrm{~cm}$, weighed $177 \mathrm{~g}$, and fitted snugly into the bomb with a clearance of about $0.008 \mathrm{~cm}$. A different monel pellet holder was used in the liner than in the series I experiments. The mass of aluminum fluoride was determined by weighing the stainless steel liner plus monel pellet holder before and after each experiment. Aluminum fluoride deposited on parts of the bomb outside the liner was brushed into the liner for weighing.
A six-cm piece of tungsten wire $(0.008 \mathrm{~cm}$ diam $)$ was used for the fuse in series II. The mass of the fuse was about $5 \mathrm{mg}$, and if burned to completion, the fuse would contribute about $50 \mathrm{~J}$ or about 0.1 percent to the energy of combustion. The use of tungsten for the fuse wire offers the advantage that its combustion leads to a volatile substance and, therefore, any unburned fuse is easily observed. Little if any unburned fuse was observed in the aluminum-Teflon combustions, but a small residue of the ends remained after the Teflon combustions. The improved estimation of the fuse energy, and the smaller amount of fuse energy apparently are significant contributing factors in the greater precision and accuracy of the measurements of series II.

\subsection{Examination of Combustion Products}

The aluminum fluoride produced in the combustions was deposited as a fine white powder covering the inner surface of the bomb, and in a larger mass in the immediate area of combustion. It was examined microscopically and found to be crystalline in appearance. The particles were regularly shaped and had dimensions of three to five microns. The x-ray diffraction pattern of the powder agreed well with data reported earlier [19]. The pattern found was that for space group $\mathrm{D}_{3}^{7}-\mathrm{R} 32$ \#155, which is trigonal. The unit cell was hexagonal with parameters $a=4.927 \AA$ and $c=12.445 \AA$, with six molecules per unit cell.

Aluminum oxide in small amounts would not be detected by the x-ray examination. However, an experiment was performed in which aluminum was burned in an equimolar mixture of fluorine and oxygen. The white powder formed as a result of the reaction was given an x-ray examination. Only aluminum fluoride was observed. Because no aluminum oxide was observed in the products of this reaction we presume that no appreciable amount of aluminum oxide would be formed by reaction of the small amount of oxygen impurity in the fluroine.

After a Teflon combustion a small amount of carbon residue was discernible $(0.2$ to $0.9 \mathrm{mg})$. No correction was applied for the unburned carbon. We assumed that carbon was formed in the same ratio to the amount of Teflon present in the combustion of aluminum-Teflon mixtures as in the combustion of Teflon alone, and that the error due to unburned material would tend to cancel out when the energy from the Teflon was subtracted from the total energy in the combustion of the mixtures.

Aside from the small amount of carbon formation, the combustions were complete, with $\mathrm{CF}_{4}$ as the only significant gaseous product in both the Teflon and aluminum-Teflon experiments. Following several experiments of each kind, the gases remaining after removal of fluorine were examined in a mass spectrometer. The observed peaks could not be attributed to fluorocarbons other than $\mathrm{CF}_{4}$ at levels of more than 0.02 percent. Oxygen, nitrogen 
and other impurities except $\mathrm{CO}_{2}$ originally present in the fluorine were still present, and the amounts were about what would have been expected if no change in them had occurred. The amount of $\mathrm{CO}_{2}$ had increased by 0.3 to 0.5 mole percent. The source of the added $\mathrm{CO}_{2}$ was not determined, and was found in both the Teflon and the aluminumTeflon experiments. No correction was made for its formation.

\section{Discussion and Results}

\subsection{Treatment of Combustion Data}

The data for the experiments recorded in tables 1-4, are enumerated in such a way that the same item number, so far as possible, refers to the same quantity in all the experiments. Items (1a) and (1b) are the masses (in vacuo) of Teflon and aluminum in the sample while item (2) is the mass (in vacuo) of aluminum fluoride recovered. Neither are corrected for impurities, however, the masses of Teflon and aluminum have been adjusted for losses in pelleting. The energy equivalent of the calorimeter, the corrected temperature rise, and the total observed energy are given by items (3), (4), and (5), respectively. The contribution of the fuse, Teflon, and impurities to the total reaction energy are given by items (6), (8), and (10), respectively. No impurity corrections were made for Teflon. The quantity $q$ (corr), item (7), includes the corrections needed to convert the observed reaction energy to that with the reactants and products in their standard states (Washburn corrections), the heat capacity corrections to convert the reaction energy from the final temperature, $30{ }^{\circ} \mathrm{C}$, to the standard reference temperature, $25^{\circ} \mathrm{C}$, and the difference $\Delta H_{298}^{\circ}-\Delta E_{298}^{\circ}$ which converts the heat of reaction measured at constant volume to that at constant pressure. Item (9) denotes the fraction of the reaction energy contributed by the combustion of aluminum given in item (1b). Items (11) and (12) give the numbers of moles of $\mathrm{Al}$ and $\mathrm{AlF}_{3}$ corrected for impurities in the aluminum and are, therefore, the most suitable measures of the quantity of reaction. Item (13) gives the reaction energy measured for the combustion of aluminum, corrected for impurities. The enthalpy change observed per mole of aluminum or per gram of Teflon introduced is listed in item (14) while the mean value is given in item (16). The corresponding values for the enthalpy change per mole based on $\mathrm{AlF}_{3}$ recovered are listed in items (15) and (17), respectively.

It is apparent from the standard deviations of the means given in items (18) and (19) that the heat observed for the combustion is more closely correlated with the mass of aluminum introduced into the bomb than with the observed masses of the aluminum fluoride formed in both series I and series II. The calculations based on the mass of aluminum fluoride formed appear less precise in series II than in series I. We attribute this difference to the use of the liner in the calorimeter bomb in series II. The liner has more than doubled the surface area of metal exposed for fluoride film formation. This would lead to greater and perhaps more erratic increases in weight due to extraneous reactions. In addition, and perhaps more important, quantitative transfer of aluminum fluoride from the other bomb parts of the liner for weighing is difficult.

Another significant difference between series I and series II is that no dependence of the observed heat of combustion on fuse-energy correction is noted in series II, though a significant dependence is noted in series I. The use of a tungsten fuse with a low total heat of combustion in series II appears to have made a significant improvement in the experiments.

\subsection{Fuse Energy Correction}

Of the corrections applied in series I to the energy measurements in the combustion of both Teflon and the aluminum-Teflon mixtures, the fuse energy correction, item (6) of table 1 and table 2 , is by far the largest and most uncertain. The magnitude of this correction was between 0.2 and 0.8 percent of the total energy involved in the combustion process. It was also observed that in each case the calculated energy of reaction was approximately a linear function of the fuse correction applied, and that in fact, a smaller spread of measurements would be obtained if no fuse energy correction were applied.

A least squares fit of the heat of combustion observed for Teflon $\left(\mathrm{Jg}^{-1}\right)$ versus the fuse energy applied, ( $q$ (fuse)), gives equation (3)

$-\Delta H_{298}^{\circ}$ ['Teflon] $\mathrm{Jg}^{-1}=10,357.6-0.16122 q$ (fuse) J.

The standard deviation of the intercept (zero fuse energy) is $18.8 \mathrm{Jg}^{-1}$ and of the slope is 0.043 . The intercept bears no necessary relation to the true heat of combustion, as some fuse must have burned in order to ignite the sample. Nevertheless, the intercept is in much closer agreement with the mean of the measurements on Teflon in series II than is the mean of series I, differing by about $7 \mathrm{Jg}^{-1}$. If we assume for series I a true fuse energy of about $43.5 \mathrm{~J}$ (the mean of that in the Teflon experiments in series II), we obtain a value for the heat of combustion of Teflon in series I of $-10,350.6 \mathrm{Jg}^{-1}$, in almost exact agreement with series II. These calculations do not justify placing any appreciable weight on the results of series I in comparison with those of series II, but do allow us to infer that the difference between series I and series II is largely attributable to the uncertainty in the values taken for the fuse energy. If the calculation of the heat of combustion of aluminum from the measurements in the aluminumTeflon experiments is made using the heat of combustion of Teflon obtained from either series I or series II, a dependence upon the applied fuse correction is still observed. A linear correlation of the heat of formation based upon the amount of aluminum in the sample and the fuse energy leads to eq (4) when the Teflon data from series I are used and 
to eq (5) when similar data from series II are applied

$$
\begin{aligned}
& -\Delta H_{f 298}^{\circ}\left[\mathrm{AlF}_{3}\right]\left(\mathrm{kJ} \mathrm{mole}^{-1}\right) \\
& =1522.06-0.082855 q \text { (fuse) J } \\
& \begin{array}{r}
-\Delta H_{298}^{\circ}\left[\mathrm{AlF}_{3}\right]\left(\mathrm{kJ} \mathrm{mole}^{-1}\right) \\
=1519.18-0.083243 q \text { (fuse) J. }
\end{array}
\end{aligned}
$$

The standard deviation of the slope is 0.019 for both eq (4) and (5) while the standard deviation of the intercept is 11.92 for eq (4) and 12.35 for eq (5). In this case, the intercepts are further away from the results of Series II than is the mean of the unadjusted experiments of series I. If we interpolate using a fuse energy of $49.8 \mathrm{~J}$ (average value for series II), we find a heat of formation for $\mathrm{AlF}_{3}$ of $-1517.9 \mathrm{~kJ}$ mole $^{-1}$ and $-1515.0 \mathrm{~kJ}$ mole ${ }^{-1}$ as calculated from eqs (4) and (5), respectively. Here again, we feel that the uncertainty in the fuse energy is so great that little weight should be given to the experiments in series I in comparison to those in series II.

In series II, the fuse energy was essentially the same $(43.5 \mathrm{~J})$ in all Teflon experiments, and also essentially the same $(49.8 \mathrm{~J})$ in all aluminum-Teflon experiments. There seems to be no question about this small difference in fuse energy as it represents the unburned ends of the fuse found after the Teflon combustions, but not found after aluminum-Teflon combustions.

\subsection{Auxiliary Data and Constants}

Buoyancy corrections for the mass of aluminum and Teflon in the combustion samples were calculated using $2.702 \mathrm{~g} \mathrm{~cm}^{-3}[20]$ and $2.31 \mathrm{~g} \mathrm{~cm}^{-3}$, respectively, for their densities. The density of Teflon was determined as part of this investigation.

The fuse energy was calculated from the masses of the fuse and the heats of formation of the fluorides formed by its combustion. For Chromel C, the calculation based on the heats of formation of $\mathrm{FeF}_{3}$, $\mathrm{CrF}_{3}$, and $\mathrm{NiF}_{2}[5]$ gives $14.5 \mathrm{~J} \mathrm{mg}^{-1}$. For the aluminum fuse wire an approximate value of $55 \mathrm{~J}$ $\mathrm{mg}^{-1}[7]$ was adopted for the heat of combustion. For combustion of tungsten, the heat of formation of $\mathrm{WF}_{6}(\mathrm{~g})$ was taken to be $-416 \mathrm{kcal}^{\text {mole }}{ }^{-1}[21]$. The combustion $5.25 \mathrm{mg}$ of tungsten wire gives $50 \mathrm{~J}$. In all cases electrical energy needed for ignition was neglected.

Washburn corrections were calculated following in general the procedure outlined by Hubbard [22] for experiments in which fluorine is an oxidant. The coefficients $\left[\frac{\partial E}{\partial P}\right]=-T\left[\frac{d B}{d T}\right]$ were found in tables based on a Lennard-Jones 6-12 potential function, as compiled by Hirschfelder, Curtiss, and Bird [23], using the appropriate force constants. The force constants used for fluorine were those determined by White, $\mathrm{Hu}$, and Johnston [24], and by Douslin [25] for carbon tetrafluoride. Force constants appropriate to the mixtures of $\mathrm{CF}_{4}$ and $\mathrm{F}_{2}$ in the reaction products were calculated from those for the pure components. For fluorine and carbon tetrafluoride, $\mathrm{Cv}_{\mathrm{v}}$ was taken to be $5.52[26]$, and $12.78[30] \mathrm{cal}$ $\mathrm{deg}^{-1}$ mole $^{-1}$, respectively. Values of Cp in cal $\mathrm{deg}^{-1}$ $\mathrm{g}^{-1}$ for aluminum, Teflon, aluminum fluoride and carbon tetrafluoride were taken to be 0.217 [27], 0.28 [28], 0.215 [29], and 0.1674 [30], respectively.

Metallic impurities and aluminum oxide present in the aluminum were assumed to react completely with fluorine. For calculation of the heats of reaction of the impurities, the heats of formation of $\mathrm{Al}_{2} \mathrm{O}_{3}, \mathrm{FeF}_{3}, \mathrm{SiF}_{4}$, and $\mathrm{CuF}_{2}$ in keal mole ${ }^{-1}$ were taken as -400.4 [31], $-235[6],-385.98$ [32], and -126.9 [5], respectively.

Atomic weights used in calculating the data were taken from the 1961 Table of Atomic Weights based on $\mathrm{C}^{12}=12$ [33].

The unit of energy is the joule. The calorie was taken as $4.1840 . \mathrm{J}$.

\subsection{Sources of Error}

Sources of scatter and systematic errors in the measurements applicable to Series II may be briefly reviewed. The loss of aluminum and Teflon in forming the pellet may not have been in proportion, as was assumed, to the amounts of each present. An estimated maximum error from this uncertainty is about 0.26 percent. The amount of unburned carbon remaining in all Teflon combustion experiments was measured and varied from 0.2 to $0.9 \mathrm{mg}$. No attempt was made to determine the carbon found in the combustion of an aluminum-Teflon pellet although carbon formation was assumed to occur in proportion to the mass of Teflon in the pellet. A maximum systematic error from this source is estimated to be about 0.18 percent.

The amounts of new fluoride film formation on the inner surfaces of the bomb may have varied from one experiment to another. This quantity was difficult to measure because of the small mass of fluoride formation needed for a significant heat effect, in comparison with the total mass of the bomb. In addition, the formation of some fluoride may occur before a heat measurement is actually begun, and further reaction with the walls may occur during the reaction of the sample. Aluminum fluoride, in the state in which it was formed, adheres tenaciously to the fluoride film on the bomb walls, and is difficult to remove. On the other hand, purging the bomb after an experiment may dislodge and carry away from the bomb minute amounts of finely divided aluminum fluoride. These factors in general, except for the uncertainties in weighing the original sample and in determining the amount of carbon residue, would tend to affect the scatter of the heat measurements based on the mass of aluminum fluoride more than those based on aluminum. The systematic difference between the measurements based on the mass of aluminum in the sample and those based on the aluminum fluoride formed in the combustion were taken as a measure of the uncertainity in the completeness of reaction, and found to be about 0.10 percent. 
While the scatter of the measurements is probably not affected by the impurity content of the sample, the uncertainty in the energy of combustion of impurities and of the amount of impurities may lead to an error which we estimate at maximum to be 0.18 percent based upon the oxygen content of the aluminum.

The presence of extremely small pieces of melted tungsten fuse imbedded in the inner wall of the liner found after the combustion experiments of series II, indicated that combustion of the tungsten fuse was not complete. Since the imbedded fuse was impossible to remove and determine quantitatively, a resulting uncertainty in the fuse energy correction ensued which we estimate to be about 0.05 percent.

In estimating the 95 percent confidence limits for the uncertainties due to the scatter of the calibration experiments, the standard deviations of the means for series II, III, and IV were multiplied by the appropriate factors of the Student $t$ distribution. Combining these and an uncertainty of 0.01 percent in the energy of combustion of benzoic acid, we obtain 0.05 percent for the uncertainty of the energy equivalent of the calorimeter.

The standard deviations of the means of the combustion experiments were also multiplied by the appropriate factors of the $t$ distribution to give the 95 percent limits of uncertainty. For the aluminumTeflon combustions, we find 0.22 percent and for the Teflon combustions 0.01 percent. Combining the various uncertainties as they would apply to aluminum, we find, as the square root of the sum of the squares, the value 0.44 percent which is equivalent to $6.6 \mathrm{~kJ} \mathrm{~mole}^{-1}\left(1.6 \mathrm{kcal} \mathrm{mole}^{-1}\right)$ uncertainty in the heat of combustion of aluminum in fluorine. We feel this is a fair estimate of the uncertainty of the heat of formation of aluminum fluoride on the basis of the present experiments.

\section{Heat of Formation of Aluminum Fluoride}

On the basis of the measurements and the calculations outlined in section 8 , we find for the heat of reaction (6) and, hence, the heat of formation of aluminum fluoride,

$$
\mathrm{Al}(\mathrm{c})+\frac{3}{2} \mathrm{~F}_{2}(\mathrm{~g})=\mathrm{AlF}_{3}(\mathrm{c})
$$

$\Delta H_{f 298}^{\circ}\left[\mathrm{AlF}_{3}(\mathrm{c})\right]=-1507.8 \pm 6.6 \mathrm{~kJ} \mathrm{~mole}^{-1}(-360.4 \pm$ $\left.1.6 \mathrm{kcal} \mathrm{mole}^{-1}\right)$.

In section 1 we outlined several previous calorimetric studies from which the heat of formation of aluminum fluoride could be determined. In that section, we listed the figures obtained by the authorities cited, which were based on data dependent upon the heat of formation of hydrogen fluoride. For this value they used the heat of formation listed in NBS Circular 500 [5], $-64.2 \mathrm{kcal} \mathrm{mole}^{-1}$. A recent reassessment of the heats of formation of $\mathrm{HF}(\mathrm{g})$ and $\mathrm{HF}(\mathrm{aq})$ by Evans [34] (see also Medvedev [35] and Feder et al. [36]) indicates that a change to a more negative value is more consistent with the available data. Evans suggests a value -64.8 keal mole ${ }^{-1}$ for $\Delta H_{f 298}^{\circ}[\mathrm{HF}(\mathrm{g})]$ and $-79.5 \mathrm{kcal} \mathrm{mole}^{-1}$ for $\Delta H_{f 298}^{\circ}[\mathrm{HF}(\mathrm{aq})]$. These values are 0.6 and 0.84 kcal mole ${ }^{-1}$ more negative than previously cited values.

Applying these data, or appropriately interpolated data for real aqueous solutions of $\mathrm{HF}$, we recalculated from the measurements of Gross et al. [7, 8], $\Delta H_{f 298}^{\circ}\left[\mathrm{AlF}_{3}(\mathrm{c})\right]=-358.8 \mathrm{kcal}$ mole ${ }^{-1}$ based on lead fluoride, and $-358.0 \mathrm{kcal}^{\mathrm{mole}}{ }^{-1}$ based on sodium fluoride and cryolite. No assessment of the maximum dispersion of these values will be made since Gross et al. do not attempt to estimate the total uncertainty in their measurements. A corresponding treatment of the measurements of Kolesov, Martynov, and Skuratov [10] leads to $\Delta H_{\text {f298 }}^{\circ}\left[\mathrm{AlF}_{3}(\mathrm{c})\right]=-358.0$ $\mathrm{kcal}_{\text {mole }}^{-1}$ with an uncertainty which they estimate at $2.0 \mathrm{kcal} \mathrm{mole}^{-1}$. The equilibrium data of Mashovets and Yudin [37], reduced to $298{ }^{\circ} \mathrm{K}$ using the third law of thermodynamics and then applying the revised heat of formation of $\mathrm{HF}(\mathrm{g})$ leads to $\Delta H_{f 298}^{\circ}\left[\mathrm{AlF}_{3}(\mathrm{c})\right]=-357.7 \pm 0.5 \mathrm{kcal} \mathrm{mole}{ }^{-1}$.

Each of the above values is still less negative than ours but with reasonable assignments of overall uncertainties, all values would fall within the assigned limits of uncertainty.

The results of this work confirm the findings of the several laboratories, whose work is mentioned above, in concluding the true enthalpy of formation of aluminum fluoride is substantially more negative than was thought until a few vears ago. The improvement of the agreement between our results and those of Gross et al., Kolesov et al., and Mashovets and Yudin, upon application of a revised value for the heat of formation of $\mathrm{HF}(\mathrm{g})$ to their results, is a substantiation of the validity of the revised value.

\section{Heat of Combustion of Teflon and the Heat of Formation of Carbon Tetrafluoride}

The measurements of series II on Teflon lead to $\Delta H_{298}^{\circ}=-10350.7 \mathrm{Jg}^{-1}$ or $-247.43 \mathrm{kcal}$ monomole ${ }^{-1}$ where a monomole refers to the unit, $-\mathrm{C}_{2} \mathrm{~F}_{4}$ -

$$
\mathrm{C}_{2} \mathrm{~F}_{4} \text { (solid polymer) }+2 \mathrm{~F}_{2}(\mathrm{~g})=2 \mathrm{CF}_{4}(\mathrm{~g}) \text {. }
$$

Estimating the contributions to the uncertainty to be 0.01 percent from the scatter of the heat measurements on Teflon, 0.04 percent from the calibration of the calorimeter, 0.09 percent from unburned carbon and 0.02 percent from the fuse energy, we find an estimated uncertainty of 0.11 percent or $11.4 \mathrm{Jg}^{-1}$ $\left(0.27 \mathrm{kcal}\right.$ monomole $\left.{ }^{-1}\right)$.

In a series of experiments on the combustion of Teflon in oxygen, Scott, Good, and Waddington [38] determined for reaction (8), $\Delta H_{298}^{\circ}=-160.3 \pm$ $0.9 \mathrm{kcal} \mathrm{mole}^{-1}$;

$\mathrm{C}_{2} \mathrm{~F}_{4}$ (solid polymer) $+\mathrm{O}_{2}(\mathrm{~g})+2 \mathrm{H}_{2} \mathrm{O}(\mathrm{l})$

$$
=2 \mathrm{CO}_{2}(\mathrm{~g})+4 \mathrm{HF}\left(\mathrm{aq}, 10 \mathrm{H}_{2} \mathrm{O}\right)
$$


and for reaction (9), $\Delta H_{298}^{\circ}=-118.8 \pm 0.5 \mathrm{kcal}$ mole $^{-1}$,

$\mathrm{C}_{2} \mathrm{~F}_{4}$ (solid polymer) $+\mathrm{O}_{2}(\mathrm{~g})=\mathrm{CO}_{2}(\mathrm{~g})+\mathrm{CF}_{4}(\mathrm{~g})$.

Using a revised value, $-76.235 \mathrm{kcal}^{\text {mole }}{ }^{-1}$ [34] for the heat of formation of $\mathrm{HF}\left(\mathrm{aq}, 10 \mathrm{H}_{2} \mathrm{O}\right)$, we calculate from their data, $\Delta H_{f 298}^{\circ}\left[\mathrm{C}_{2} \mathrm{~F}_{4}\right.$ (solid polymer)] $=-196.11 \mathrm{kcal}$ monomole ${ }^{-1}$, and $\Delta H_{f 298}^{\circ}\left[\mathrm{CF}_{4}(\mathrm{~g})\right]=$ $-220.86 \mathrm{kcal} \mathrm{mole}^{-1}$.

Using the value thus calculated for $\mathrm{C}_{2} \mathrm{~F}_{4}$ (solid polymer) with our results for reaction (7), we calculate $\Delta H_{f 298}^{\circ}\left[\mathrm{CF}_{4}(\mathrm{~g})\right]=-221.77 \mathrm{kcal} \mathrm{mole}^{-1}$.

Here again the results are in much better agreement when the revised value for the heat of formation of hydrogen fluoride is used than if the previously accepted value had been used. The two values for $\Delta H_{f 2 r}^{\circ}\left[\mathrm{CF}_{4}(\mathrm{~g})\right]$ are in agreement within the limits of experimental error cited. However, it should be recognized that measurements based upon $\mathrm{C}_{2} \mathrm{~F}_{4}$ (solid polymer) as an intermediate are subject to a possible limitation in reproducibility because Teflon is not a well defined substance. In the comparison of our results with those of Scott et al., it is therefore necessary to bear in mind the fact that different preparations of Teflon were used in the two experimental studies.

\section{References}

[1] Baud, E., Compt. Rend. 135, 1103-6 (1902).

[2] Baud, E., Ann. Chim. Phys. 1, 8-71 (1904).

[3] Wartenberg, H. v., Z. Anorg. Allgem. Chem. 151, 326-30 (1926).

[4] Bichowsky, F. R., and Rossini, F. D., The Thermochemistry of the Chemical Substances (Reinhold Publishing Corp., New York, 1936).

[5] Rossini, F. D., Wagman, D. D., Evans, W. H., Levine, S., and Jaffa, I., Selected Values of Chemical Thermodynamic Properties, NBS Circ. 500 (U.S. Government Printing Office. Washington, 25, D.C. 1952).

[6] Brewer, L., Bromley, L. A., Gilles, P. W., and Lofgren, N., "The Thermodynamic Properties of the Halides," Paper 6, Chemistry and Metallurgy of Miscellaneous Materials: Thermodynamics, L. L. Quill, Editor, (McGraw-Hill Book Company, Inc., New York, 1950).

[7] Gross, P., Hayman, C., and Levi, D. L., Trans. Faraday Soc. 50, 477-80 (1954).

[8] Gross, P., Hayman, C., and Levi, D. L., "The Heats of Formation of Cryolite and the Aluminum Fluorides," pp. 903-908 (Part 2). International Symposium on the Physical Chemistry of Process Metallurgy, Pittsburgh, 1959. Physical Chemistry of Process Metallurgy, G. R. St. Pierre, Editor, (Interscience Publishers, New York, 1961).

[9] Coughlin, J. P., J. Am. Chem. Soc. 80, 1802-4 (1958).
[10] Kolesov, V. P., Martynov, A. M., and Skuratov, S. M., Zh. Neorgan. Khim. 6, 2623-6 (1961).

[11] Hubbard, W. N., Settle, J. L., and Feder, J. M., Pure Applied Chem. 2, 39-44 (1961).

[12] Kubaschewsky, O., and Hopkins, B. E., Oxidation of Metals and Alloys (Butterworth Scientific Publications, London, 1953), pp. 130-7, 180.

[13] Werner, O., Metall 4, 9-12 (1950).

[14] Armstrong, G. T., and Jessup, R. S., J. Res. NBS 64 A, 49-59 (1960).

[15] Dickinson, H. C., Bul. BS 11, 189-257 (1914).

[16] Prosen, E. J., Johnson, W. H., and Pergiel, F. Y., J. Res. Natl. Bur. Std. 62, 43-7 (1959).

[17] Coops, J., Jessup, R. S., and Van Nes, K. "Calibration of Calorimeters for Reactions in a Bomb at Constant Volume," Chapter 3, Experimental Thermochemistry, F. D. Rossini, Editor, (Interscience Publishers, Inc., New York, 1956).

[18] Jessup, R. S., NBS Mono. 7, February 26, 1960.

[19] Staritzky, E., and Asprey, L. B., Anal. Chem. 99, 984 (1957).

[20] Edwards, D. J., and Moorman, T. A., Chem. \& Met. Eng. 24, 61-4 (1921).

[21] Meyers, O. E., and Brady, A. P., J. Phys. Chem. 64, 591-4 (1960).

[22] Hubbard, W. N., "Fluorine Bomb Calorimetry," Chapter 6, Experimental Thermochemistry, Vol. II, H. A. Skinner, Editor, (Interscience Publishers, Inc., New York, N.Y., 1962).

[23] Hirschfelder, J. O., Curtiss, C. F., and Bird, R. B., Molecular Theory of Gases and Liquids, (John Wiley \& Sons, New York, N.Y., 1954), 1114-5.

[24] White, D., Hu, J. H., and Johnston, H. L., J. Chem. Phvs. 21, 1149-52 (1953).

[25] Douslin, D. R., "Pressure-Volume-Temperature Relations and Intermolecular Potentials for Methane and Tetrafluoromethane," Paper 11, Progress in International Research on Thermodynamic and Transport Properties, J. F. Masi and D. H. Tsai, Editors, (Academic Press, New York, N.Y., 1962).

[26] Evans, W. H., Munson, T. R., and Wagman, D. D., J. Res. NBS $\mathbf{5 5}, 147-64$ (1955).

[27] Giauque, W. F., and Meads, P. F., J. Am. Chem. Soc. 63, 1897-1901 (1941).

[28] Good, W. D., Scott, D. W., and Waddington, G., J. Phys. Chem. 60, 1080-9 (1956).

[29] O'Brien, C. J., and Kelley, K. K., J. Am. Chem. Soc. 79, 5616-18 (1957).

[30] Kellev, K. K., U.S. Bur. Mines Bull. 584 (1960).

[31] Mah, A. D., J. Phys. Chem. 61, 1572-3 (1957).

[32] Wise, S. S., Margrave, J. L., Feder, H. M., and Hubbard, W. N., J. Phys. Chem. 6\%, 815-821 (1963).

[33] Cameron, A. E., and Wichers, E., J. Am. Chem. Soc. 84, $4175-97$ (1962).

[34] Evans, W. H. (NBS, private communication, 1964).

[35] Medvedev, V. A., Zh. Fiz. Khim. 3g (6), 1403-6 (1963).

[36] Feder, H. M., Hubbard, W. N., Wise, S. S., and Margrave, J. L., J. Phys. Chem. 6\%, 1148-50 (1963).

[37] Mashovets, V. P., and Yudin, B. F., Izv. Vysshikh Uchebn. Zavedenii, Tsvetn. Met. 5, 95-105 (1962).

[38] Scott, D. W., Good, W. D., and Waddington, G., J. Am. Chem. Soc. 7 \%, 245-6 (1955).

(Paper 69A2-335) 